\title{
Optimization of Nutrients and Process Parameters for Improved Production of Bioactive Metabolite Butyrolactone I by Aspergillus terreus strains under Submerged Fermentation
}

\author{
D.L. Rudresh ${ }^{1,2 *}$, Ratnadeep Paul Choudhury ${ }^{1}$ and Anamika Nakul ${ }^{1}$ \\ ${ }^{1}$ ITC Life Sciences \& Technology Centre, $1^{\text {st }}$ Main, 1st Phase, Peenya Industrial Area, \\ Bangalore-560058, India \\ ${ }^{2}$ Departmnet of Agricultural Microbiology, College of Horticulture, University of \\ Horticultural Sciences, Navanagar, Bagalkot, Karnataka, India \\ *Corresponding author
}

\section{A B S T R A C T}

\section{Keywords \\ Aspergillus terreus, Butyrolactone I, Nutrient concentrations, Fermentation conditions \\ Article Info \\ Accepted: \\ 07 March 2019 \\ Available Online: \\ 10 April 2019}

Aspergilli, a large and diverse genus of ubiquitous filamentous fungi are the source of diverse secondary metabolites that can be used in the development of medications to treat diseases. Butyrolactone $\mathrm{I}$ is produced as a secondary metabolite by A. terreus. Butyrolactone I is a potent inhibitor of the eukaryotic cyclin-dependent kinases (CDK's), protein kinases which control cell progression in all eukaryotes. Cyclin-dependent kinases are involved in numerous diseases in human beings like, cancer, stroke, diabetes, inflammation and AIDS. Butyrolactone I can become a life saving molecule in the above said diseases. In the present investigation the concentrations of carbon, nitrogen and phosphate sources and different fermentation conditions like temperature, media $\mathrm{pH}$, agitation and incubation period were screened for their effect on the production of Butyrolactone I by two strains of A. terreus. The optimum nutrient concentrations and fermentation conditions for maximum production of Butyrolactone I were identified.

\section{Introduction}

Microorganisms are virtually unlimited source of novel chemical structures with many therapeutic applications. Aspergillus, a large and diverse genus of filamentous fungi, is renowned for the production of diverse secondary metabolites (Domsch et al., 1980, Roy et al., 1999 and Hasegawa et al., 2007). Among the species of Aspergillus, A. terreus a common soil fungus is a prolific producer of secondary metabolites. Few of the compounds that are produced by A. terreus are as pulvinone (Takahashi et al., 1978), asterric acid (Curtis et al., 1960), asterriquinone (Kaji et al., 1984), butyrolactone I (Kiriyama et al., 1977), lovastatin (Alberts et al., 1980 and Greenspan et al., 1985), Terreulactone A, B, C \& D (Cho et al., 2003) and Territrem A, B \& C (Ling et al., 1982 \& 1984).

These secondary metabolites have evolved to confer selective advantage to the producing organisms, with biosynthesis generally 
triggered by specific environmental conditions or by specific substrate or inducer.

These metabolites from A. terreus have several applications for example Lovastatin (mevinolin) is used as a cholesterol lowering agent (Alberts et al., 1980), Terrein and terreicacids have antibiotic activity (Han et al., 2010), Terreulactone A, B, C \& D are potent Acetylcholinesterase inhibitors (Cho et al., 2003).

Butyrolactone I ((R)-methyl 4-hydroxy-2-(4hydroxy-3-(3-methylbutan-2-enyl) benzyl)-3(4-hydroxyphenyl)-5-oxo-2, 5-dihydrofuran2-carboxylate) a secondary metabolite of $A$. terreus discovered in 1977 (Kiriyama et al., 1977) has antiproliferative activity against colon and pancreatic carcinoma, human lung cancer and prostatic cancer cell lines (Kiriyama et al., 1977). It selectively inhibits eukaryotic cyclin-dependent kinases (CDKs), which play important roles in cell cycle progression, neuronal functions, apoptosis and transcription in mammalian cells (Kitagawa et al., 1994). Cyclin-dependent kinases are involved in numerous diseases, among which cancer, stroke, diabetes, polycystic kidney disease, glomerulonephritis, inflammation, and AIDS are major diseases (Malumbres and Barbacid, 2005).

It has been postulated that fungal growth and metabolite production are influenced by substrates and environmental factors such as moisture, temperature, incubation time (Sinha, 1973; Hesseltine, 1974; Schimmel and Parsons, 1999). This suggests that nutritional and environmental conditions play a major role in the production of secondary metabolites.

In fermentation process, most of the carbon, nitrogen, phosphate and amino acid sources needed for fungal growth interfere with the biosynthesis of many secondary metabolites.
The standardization of fermentation medium with nutrient profile for the bioactive producing organisms is a critical and important process as the medium composition can significantly affect the product yield.

The objective of the present study was to optimize the nutrients and fermentation conditions for enhanced Butyrolactone I production by strains of $A$. terreus.

\section{Materials and Methods}

\section{Materials}

Sucrose, peptone, $\mathrm{KH}_{2} \mathrm{PO}_{4}$, Biotin and all the nutrients used in the present study were procured from Fisher Scientific (Mumbai, India). Solvents used in the present study were obtained from Merck Chemicals (Mumbai, India). Purified Butyrolactone I was provided by Inogent Technologies (Hyderabad, India).

\section{Microorganisms and maintenance}

Fungal cultures of $A$. terreus ITC-01, $A$. terreus ITC-14 used in the present study were obtained from the Microbial Culture Collection, Division of Microbiology, ITC R \& D Centre, Peenya, Bangalore, India. Fungal cultures were maintained routinely on a potato dextrose agar medium (Himedia Laboratories Pvt. Ltd., Mumbai, India) and subcultured in every 30 -day interval.

\section{Inoculum preparation}

Aspergillus terreus strains ITC-01 and ITC-14 were cultured on solidified potato dextrose agar Petri plates and incubated at $28 \pm 2^{0} \mathrm{C}$. Conidiophores obtained from the 10 day old colonies were used as inoculum source at the rate of one $9 \mathrm{~mm}$ disc per flask containing $100 \mathrm{ml}$ nutrient medium in all our experiments. 


\section{Fermentation process}

All the experiments were carried out in 100 $\mathrm{ml}$ of media broth prepared in $500 \mathrm{ml}$ of conical flasks (Borosil, India) in triplicates. The culture media were sterilized at $121^{\circ} \mathrm{C}$ for 15 minutes. The Vogel's salt solution-50X concentration (Vogel, 1956) at the rate of 20 $\mathrm{ml} / \mathrm{L}$ was used commonly in all the treatments.

\section{Nutrient optimization studies}

Carbon, nitrogen and phosphate are the major nutrients required for the normal growth as well as secondary metabolite production by microorganisms. The concentrations of these 3 major nutrients were optimized for maximum production of secondary metabolite, Butyrolactone I.

\section{Optimization of carbon source concentration}

Sucrose was used as the source of carbon. The different concentrations of sucrose ranging from 1.5 to $6.50 \%$ were screened for its effect on the production of Butyrolactone I by two strains of A. terreus.

Optimization of nitrogen source concentration

Peptone (Fisher Scientific, Mumbai, India) was used as a source of nitrogen. Concentrations of peptone from 0.3 to $0.9 \%$ were screened for its effect on the production of Butyrolactone I.

\section{Optimization of phosphate source concentration}

$\mathrm{KH}_{2} \mathrm{PO}_{4}$ was used as a source of phosphorus. The concentrations of $\mathrm{KH}_{2} \mathrm{PO}_{4}$ from 0.05 to $1.0 \%$ were tested for its effect on the production of Butyrolactone I.

\section{Process optimization studies}

The fermentation or culture conditions like, $\mathrm{pH}$ of the medium, incubation temperature, incubation time, and agitation play an important role in inducing the secondary metabolites production by microorganisms (Wefky et al., 2009; Lopez et al., 2004). In the present study we have investigated the effect of different physiological parameters mentioned above on the production of Butyrolactone I by two strains of A. terreus. Same media composition was used in all the process optimization studies (Vogel's 50X salt solution (Vogel, 1956) $20 \mathrm{ml} / \mathrm{L}$, Sucrose: $60 \mathrm{~g} / \mathrm{L}, \mathrm{KH}_{2} \mathrm{PO}_{4}$ : $0.75 \mathrm{~g} / \mathrm{L}$, Bacto peptone: 3.0 $\mathrm{g} / \mathrm{L}) .100 \mathrm{ml}$ of media broth in $500 \mathrm{ml}$ Borosil conical flask was used in all the experiments. The incubation period for all the process optimization studies except studies on effect of incubation period was 6 days.

\section{Effect of pH}

To study the effect of initial media $\mathrm{pH}$ on the production of Butyrolactone I, initial $\mathrm{pH}$ of the media was adjusted over the range from 4.0 to 7.0 (Table 4 ) by using $1 \mathrm{~N} \mathrm{NaOH}$ or $1 \mathrm{~N}$ HCL before the media sterilization and used.

\section{Effect of temperature}

Flasks containing $100 \mathrm{ml}$ of inoculated media were incubated at various temperatures ranging from 20 to $35^{\circ} \mathrm{C}$ (Table 5) in a cooling incubator (Labtech India Pvt. Ltd., Hyderabad, India).

\section{Effect of agitation}

To study the effect of agitation on the production of Butyrolactone I. The inoculated flasks were agitated at $100 \mathrm{rpm}$ for different time period viz., up to $6 \mathrm{~h}, 12 \mathrm{~h}, 24 \mathrm{~h}$ after inoculation and continuous agitation for whole incubation period in an orbital shaker at room temperature. 


\section{Effect of incubation time}

To study the effect of time course on Butyrolactone I production, inoculated flasks were incubated in cooling incubator (Labtech, India) at $28 \pm 2^{\circ} \mathrm{C}$ for different time period ranging from 120 to 264 hours (Table 7).

Effect of optimized nutrient media compositions and fermentation conditions on the yield of butyrolactone I

Nutrient media (Medium II in Table 8) was prepared by using the optimized concentrations of carbon, nitrogen, phosphorus and $\mathrm{pH}$ from the above nutrient optimization studies. The media broths were inoculated with two strains of $A$. terreus ITC$01 \&$ ITC-14 and were grown in optimized growth conditions and evaluated for their ability to produce enhanced Butyrolactone I and compared with two other media compositions viz., Vogel's medium (Control medium in Table 8) and Vogel's medium with enriched carbon source (sucrose)(Medium I in Table 8) concentration to identify the best media profile for the enhanced production of Butyrolactone I from A, terreusstrains.

\section{Harvesting of fungal biomass}

After the incubation period the fungal biomass in the culture flasks were harvested by filtering the contents of the flask using what man no.1filter paper. The harvested fungal biomass was pressed between the folds of the blotting sheets to remove excess water, air dried for 30 minutes and used for subsequent solvent extraction.

\section{Extraction of Butyrolactone I}

The fungal biomass obtained was taken in 250 $\mathrm{ml}$ conical flask mixed with ethyl acetate in the ratio of 1:10 (biomass: solvent: 1: $10 \mathrm{w} / \mathrm{v}$ ) and agitated on a rotary shaker at 100 RPM for 20 minute in room temperature. The agitated mixture was filtered using what man no. 1 filter paper and taken in a separating funnel. The solvent layer was separated and evaporated using Rota vapor (Ika, Germany) to concentrate the extraction of bioactives.

\section{Butyrolactone estimation by HPLC}

\section{Sample preparation for HPLC}

Known weight of the concentrated bioactives extract from fungal biomass was dissolved in known quantity of Methanol and subjected for HPLC assay.

\section{HPLC assay procedure}

The butyrolactone I was assayed using HPLC with an Agilent 1200 serial system equipped with a quaternary pump, online degasser, auto-sampler, column heater and variable wavelength detector. Separation was achieved on a reversed phase column (Agilent Hypersil $\mathrm{C} 18,2.1 \mathrm{~mm} \times 200 \mathrm{~mm}$, pore size $5 \mu \mathrm{m}$, PN 79916AA-572, USA).

The Butyrolactone was eluted isocratically with a mobile phase of acetonitrile and water $(40: 60 \mathrm{v} / \mathrm{v})$ at a flow rate of $0.5 \mathrm{ml} / \mathrm{min}$ with detection at $300 \mathrm{~nm}$. Elution profiles were monitored and peaks were identified by UV absorbance at $300 \mathrm{~nm}$. The temperature was maintained at $25^{\circ} \mathrm{C}$. The injection volume was $10 \mu \mathrm{L}$. Authentic standards of Butyrolactone I was used to confirm the retention time and quantity of each compound in fungal extracts.

\section{Data analysis}

The data collected in this study was subjected to analysis of variance (ANOVA) and comparison between treatment means was made using Duncan's multiple range test (DMRT) (Little and Hills, 1978). 


\section{Results and Discussion}

The first step in utilizing the strains producing secondary metabolites is to modify the basic production medium and conditions to obtain maximum yield of the desired compound. This was accomplished by screening and optimizing different nutrient concentrations and process parameters.

\section{Optimization of nutrients}

The experimental results obtained from nutrient optimization studies for maximizing the production of Butyrolactone I from two strains of A.terreus are presented in Tables 1 to 3 . The result from nutrient optimization studies revealed that, among the different sources of nutrients carbon plays a major role in the production of Butyrolactone I followed by nitrogen and phosphorus nutrients.

Among the different concentrations of carbon source, $6.0 \%$ sucrose was found to be the optimum for maximum production of Butyrolactone I for both the strains of fungi (Table 1). At $6.0 \%$ sucrose concentration the yield of Butyrolactone I was 28.43 and 24.97 $\mathrm{mg}$ in ITC-01 and ITC-14 strain respectively, which was significantly higher compare to all other concentrations of sucrose. Similarly the nitrogen source (peptone) concentration at 3.0 $\mathrm{g} / \mathrm{L}$ produced Butyrolactone I yield of 17.24 (ITC-01) and 22.28 (ITC-14) mg per $100 \mathrm{ml}$ media which was significantly higher compare to all other peptone concentrations, therefore the peptone concentration at $3.0 \mathrm{~g} / \mathrm{L}$ was found to be the optimum concentration (Table 2). The peptone concentration above $0.3 \mathrm{~g} / \mathrm{l}$ was found to reduce Butyrolactone I production significantly in both the strains of A. terreus.

In case of phosphorus source, the concentration of $\mathrm{KH}_{2} \mathrm{PO}_{4}$ at the rate of 0.75 $\mathrm{g} / \mathrm{L}$ in case of ITC-01 and $1.0 \mathrm{~g} / \mathrm{L}$ in case of ITC-14 was found to produce maximum yield of Butyrolactone I (34.81 and $33.63 \mathrm{mg}$ Butyrolactone I in ITC-01 and ITC-14 respectively) (Table 3). Biosynthesis of several secondary metabolites by microorganisms is controlled by phosphate concentration (Martin, 1977).

In the present investigation the fermentation medium with higher concentration of carbon source and reduced concentration of nitrogen and phosphorus produced maximum yield of Butyrolactone I. Our results are in conformity with Lopez et al., (2004), who also observed higher production of bioactive compound lovastatin by high $\mathrm{C} / \mathrm{N}$ ratio in the medium.

\section{Optimization of fermentation process parameters}

In the present experiment the process parameters viz., initial media $\mathrm{pH}$, incubation temperature, agitation and incubation time were optimized for maximum production of Butyrolactone I by A. terreusstrains ITC-01 and ITC-14. The results of the studies on optimization of fermentation conditions are presented in Tables 4 to 7 .

\section{Effect of pH}

The observations (Table 4) from the experiment to find out the effect of media $\mathrm{pH}$ on Butyrolactone I production clearly showed that $\mathrm{pH}$ in the range of 6.5 to 7.0 to be the best $\mathrm{pH}$ range for maximum yield of Butyrolactone I by ITC-01 and $\mathrm{pH} 6.5$ for ITC-14. Although the fungi can grow on wide range of $\mathrm{pH}$ ranging from 2 to 8.5 the maximum production of toxins and secondary metabolites occur at $\mathrm{pH}$ near to alkaline conditions (Lie and Marth, 1968). In the present study both the strains of A. terreus produced highest Butyrolactone $\mathrm{I}$ at a $\mathrm{pH}$ of 6.5 (37.64 and $47.01 \mathrm{mg}$ of Butyrolactone I by ITC-01 and ITC-14 respectively) which is in conformity with the findings of Lie and Marth (1968). 


\section{Effect of incubation temperature}

Temperature is one of the most important environmental process parameter influencing the growth and production of secondary metabolites by fungi (Castella et al., 1999, Ramos et al., 1998). Both the strains of $A$. terreus produced maximum Butyrolactone I at incubation temperature of $30^{\circ} \mathrm{C}$ (Table 5), hence temperature of $30^{\circ} \mathrm{C}$ was found to be the optimum for the production of Butyrolactone I. At $30^{\circ} \mathrm{C}$ ITC-01 and ITC-14 strains produced 19.38 and $36.25 \mathrm{mg}$ of Butyrolactone I per $100 \mathrm{ml}$ nutrient media, which was highest, compared to all other temperature treatments (Table 5). The production of Butyrolactone I by both the $A$. terreus strains increased with increase in temperature from $20^{\circ} \mathrm{C}$ and reached maximum production at $30^{\circ} \mathrm{C}$. The incubation temperature above $35^{\circ} \mathrm{C}$ was found to reduce the production of Butyrolactone I. LealSanchez et al., (2002) and Lopez et al., (2004) reported that temperature to have significant effects on the production of the bioactive compounds which is in agreement with our study.

\section{Effect of agitation}

The observations from the experiment (Table
6) showed that fermentation process at stationery and/or agitation up to initial $12 \mathrm{~h}$ after inoculation to will give maximum yield of Butyrolactone I compare to fermentation process in complete agitation. The yield of Butyrolactone I was same in Stationery, 6h agitation and $12 \mathrm{~h}$ agitation (Table 6).

\section{Effect of incubation time}

Among all the parameters of fermentation process, incubation time was found to be the most influencing factor in the production of Butyrolactone I by A. terreus strains. The observations from the studies (Table 7) showed the maximum production of Butyrolactone $\mathrm{I}$ at 10 days of incubation. After 10 days of incubation period the yield of Butyrolactone I was found to reduce significantly (data not shown). At 10 days ITC-01 produced $78.01 \mathrm{mg}$ of Butyrolactone I per $100 \mathrm{ml}$ of media whereas ITC-14 produced $60.62 \mathrm{mg}$ (Table 7). Our study is in conformity with the studies of Panda et al., (2007) and Wefky et al., (2009) who also showed that production of secondary metabolites viz., lovastatin and other antibiotic compounds by $A$. terreus and Enterococcus faecium was influenced by incubation time.

Table.1 Effect of different concentrations of carbon source on the yield of Butyrolactone I

\begin{tabular}{|l|l|l|l|}
\hline SL. & Sucrose (g/l) & \multicolumn{3}{|c|}{ Yield of Butyrolactone I mg/100 ml media } \\
\cline { 3 - 4 } & & A. terreus ITC-01 & A. terreus ITC-14 \\
\hline $\mathbf{1}$ & 15 & $4.37^{\mathrm{d}}$ & $\mathbf{1 . 1 0}^{\mathrm{d}}$ \\
\hline $\mathbf{2}$ & 30 & $10.17^{\mathrm{c}}$ & $\mathbf{5 . 6 5}^{\mathrm{c}}$ \\
\hline $\mathbf{3}$ & 45 & $19.96^{\mathrm{b}}$ & $\mathbf{2 3 . 9 8 ^ { \mathrm { b } }}$ \\
\hline $\mathbf{4}$ & 60 & $28.43^{\mathrm{a}}$ & $\mathbf{2 4 . 9 7 a}$ \\
\hline $\mathbf{5}$ & 65 & $27.45^{\mathrm{a}}$ & $\mathbf{2 4 . 0 1} \mathbf{a}$ \\
\hline LSD $(\mathbf{P} \leq \mathbf{0 . 0 5})$ & $\mathbf{1 . 0 5 5}$ & $\mathbf{0 . 6 2 2 2}$ \\
\hline
\end{tabular}

Note: 1. Mean values in each column with the same superscript(s) do not differ significantly by DMRT $(\mathrm{P}=0.05)$, 2. The growth medium contained Vogel's salt solution (50X)@ $20 \mathrm{ml} / \mathrm{L}$ in addition to sucrose. 3. Fermentation was carried out at room temperature 
Table.2 Effect of different concentrations of nitrogen source on the yield of Butyrolactone I

\begin{tabular}{|l|l|l|l|}
\hline SL. & Peptone (g/l) & \multicolumn{3}{|c|}{ Yield of Butyrolactone I mg/100 ml media } \\
\cline { 3 - 4 } & & A. terreus ITC-01 & A. terreus ITC-14 \\
\hline $\mathbf{1}$ & 3 & $17.24^{\mathrm{a}}$ & $\mathbf{2 2 . 2 8}^{\mathrm{a}}$ \\
\hline $\mathbf{2}$ & 5 & $14.90^{\mathrm{b}}$ & $\mathbf{1 6 . 9 1}^{\mathrm{b}}$ \\
\hline $\mathbf{3}$ & 7 & $11.81^{\mathrm{c}}$ & $\mathbf{1 3 . 2 3}^{\mathrm{c}}$ \\
\hline $\mathbf{4}$ & 9 & $9.63^{\mathrm{d}}$ & $\mathbf{9 . 2 2 d}$ \\
\hline LSD $(\mathbf{P} \leq \mathbf{0 . 0 5})$ & $\mathbf{1 . 5 4 5}$ & $\mathbf{3 . 6 5 6}$ \\
\hline
\end{tabular}

Note: 1 . Mean values in each column with the same superscript(s) do not differ significantly by DMRT $(\mathrm{P}=0.05)$, 2. The growth medium contained Vogel's salt solution (50X)@20 ml/L and sucrose @60 g/l in addition to Peptone. 3. Fermentation was carried out at room temperature

Table.3 Effect of different concentrations of phosphorus source on the yield of Butyrolactone I

\begin{tabular}{|c|c|c|c|}
\hline \multirow[t]{2}{*}{ SL. } & \multirow{2}{*}{$\mathrm{KH}_{2} \mathrm{PO}_{4}(\mathrm{~g} / \mathrm{l})$} & \multicolumn{2}{|c|}{ Yield of Butyrolactone I mg/100 ml media } \\
\hline & & A. terreus ITC-01 & A. terreus ITC-14 \\
\hline 1 & 0.5 & $24.36^{\mathrm{c}}$ & $\mathbf{3 3 . 5 3}^{\mathrm{a}}$ \\
\hline 2 & 0.75 & $34.81^{\mathrm{a}}$ & $21.50^{c}$ \\
\hline 3 & 1.0 & $23.84^{\mathrm{c}}$ & $33.63^{\mathrm{a}}$ \\
\hline 4 & 1.25 & $29.51^{b}$ & $29.08^{b}$ \\
\hline \multicolumn{2}{|c|}{ LSD $(P<0.05)$} & 1.917 & 1.503 \\
\hline
\end{tabular}

Note: 1. Mean values in each column with the same superscript(s) do not differ significantly by DMRT $(\mathrm{P}=0.05)$, 2. The growth medium contained Vogel's salt solution (50X)@ $20 \mathrm{ml} / \mathrm{L}$ and sucrose @ $60 \mathrm{~g} / \mathrm{l}$ in addition to $\mathrm{KH}_{2} \mathrm{PO}_{4}$. 3. Fermentation was carried out at room temperature

Table.4 Effect of $\mathrm{pH}$ on the yield of Butyrolactone I at room temperature

\begin{tabular}{|l|l|l|l|}
\hline SL. & Initial media $\mathbf{p H}$ & \multicolumn{3}{|c|}{ Yield of Butyrolactone I mg/100 ml media } \\
\cline { 3 - 5 } & & A.terreus ITC-01 & A. terreus ITC-14 \\
\hline $\mathbf{1}$ & 4.0 & $28.43^{\mathrm{c}}$ & $\mathbf{3 8 . 9 9}^{\mathbf{c}}$ \\
\hline $\mathbf{2}$ & 4.5 & $22.6^{\mathrm{d}}$ & $\mathbf{4 0 . 8 5}^{\mathbf{b}}$ \\
\hline $\mathbf{3}$ & 5.0 & $21.56^{\mathrm{d}}$ & $\mathbf{3 1 . 0 6}^{\mathrm{e}}$ \\
\hline $\mathbf{4}$ & 5.5 & $29.31^{\mathrm{c}}$ & $\mathbf{3 2 . 2 1}^{\mathrm{e}}$ \\
\hline $\mathbf{5}$ & 6.0 & $36.57^{\mathrm{a}}$ & $\mathbf{2 8 . 8 0}^{\mathrm{f}}$ \\
\hline $\mathbf{6}$ & 6.5 & $37.64^{\mathrm{a}}$ & $\mathbf{4 7 . 0 1}^{\mathrm{a}}$ \\
\hline $\mathbf{7}$ & 7.0 & $34.58^{\mathrm{b}}$ & $\mathbf{3 6 . 3 9}^{\mathrm{d}}$ \\
\hline LSD $(\mathbf{P} \leq \mathbf{0 . 0 5})$ & $\mathbf{1 . 3 9 3}$ & $\mathbf{1 . 6 2 5}^{\mathrm{n}}$ \\
\hline
\end{tabular}

Note: 1 . Mean values in each column with the same superscript(s) do not differ significantly by DMRT $(\mathrm{P}=0.05)$, 2. The growth medium contained Vogel's salt solution (50X)@ $20 \mathrm{ml} / \mathrm{L}$, sucrose @ $60 \mathrm{~g} / \mathrm{l}, \mathrm{KH}_{2} \mathrm{PO}_{4} @ 0.75 \mathrm{~g} / \mathrm{l}$ and Peptone @ $3.0 \mathrm{~g} / \mathrm{l}$. 3. Fermentation was carried out at room temperature 
Table.5 Effect of incubation temperature on the yield of Butyrolactone I

\begin{tabular}{|l|l|l|l|}
\hline \multirow{2}{*}{ SL. } & Temperature & \multicolumn{2}{|c|}{ Yield of Butyrolactone I mg/100 ml media } \\
\cline { 3 - 4 } & & A.terreus ITC-01 & A. terreus ITC-14 \\
\hline $\mathbf{1}$ & $20^{\circ} \mathrm{C}$ & $2.96^{\mathrm{d}}$ & $\mathbf{1 . 3 8}^{\mathbf{c}}$ \\
\hline $\mathbf{2}$ & $25^{\circ} \mathrm{C}$ & $15.11^{\mathrm{c}}$ & $\mathbf{2 7 . 2 1}^{\mathbf{b}}$ \\
\hline $\mathbf{3}$ & $30^{\circ} \mathrm{C}$ & $19.38^{\mathrm{a}}$ & $\mathbf{3 6 . 2 5}^{\mathrm{a}}$ \\
\hline $\mathbf{4}$ & $35^{\circ} \mathrm{C}$ & $16.52^{\mathrm{b}}$ & $\mathbf{2 5 . 0 1}^{\mathbf{b}}$ \\
\hline & LSD $(\mathbf{P} \leq \mathbf{0 . 0 5})$ & $\mathbf{0 . 4 4 7}$ & $\mathbf{2 . 2 6 7}^{\mathrm{0}}$ \\
\hline
\end{tabular}

Note: 1. Mean values in each column with the same superscript(s) do not differ significantly by DMRT $(\mathrm{P}=0.05)$, 2. The growth medium contained Vogel's salt solution (50X)@ $20 \mathrm{ml} / \mathrm{L}$, sucrose @ $60 \mathrm{~g} / \mathrm{l}, \mathrm{KH}_{2} \mathrm{PO}_{4} @ 0.75 \mathrm{~g} / \mathrm{l}$ and Peptone @ $3.0 \mathrm{~g} / \mathrm{l}$.

Table.6 Effect of agitation on the yield of Butyrolactone I at room temperature

\begin{tabular}{|c|c|c|c|}
\hline \multirow[t]{2}{*}{ SL. } & \multirow[t]{2}{*}{ Agitation (100 rpm) } & \multicolumn{2}{|c|}{ Yield of Butyrolactone I mg/100 ml media } \\
\hline & & A. terreus ITC-01 & A. terreus ITC-14 \\
\hline 1 & Stationery & $26.31^{\mathrm{a}}$ & $27.29^{\mathrm{a}}$ \\
\hline 2 & Initial $6 \mathrm{~h}$ after incubation & $25.11^{\mathrm{a}}$ & $28.12^{\mathrm{a}}$ \\
\hline 3 & Initial $2 \mathrm{~h}$ after incubation & $25.63^{\mathrm{a}}$ & $27.10^{\mathrm{a}}$ \\
\hline 4 & Up to $24 \mathrm{~h}$ after incubation & $13.39^{b}$ & $24.73^{b}$ \\
\hline 5 & Complete agitation & $5.44^{\mathrm{c}}$ & $6.97 \mathrm{c}$ \\
\hline \multicolumn{2}{|c|}{ LSD $(P \leq 0.05)$} & 1.604 & 1.043 \\
\hline
\end{tabular}

Note: 1. Mean values in each column with the same superscript(s) do not differ significantly by DMRT $(\mathrm{P}=0.05)$, 2. The growth medium contained Vogel's salt solution(50X)@20 ml/L, sucrose @60 g/l, KH $\mathrm{KH}_{4} @ 0.75 \mathrm{~g} / \mathrm{l}$ and Peptone @ $3.0 \mathrm{~g} / \mathrm{l}$

Table.7 Effect of incubation period on the yield of Butyrolactone I at room temperature

\begin{tabular}{|l|l|l|l|}
\hline SL. & Incubation days & \multicolumn{3}{|c|}{ Yield of Butyrolactone I mg/100 ml media } \\
\cline { 3 - 4 } & & A. terreus ITC-01 & A. terreus ITC-14 \\
\hline $\mathbf{1}$ & 5 days & $57.38^{\mathrm{b}}$ & $\mathbf{2 2 . 8 1}^{\mathrm{f}}$ \\
\hline $\mathbf{2}$ & 6 days & $57.49^{\mathrm{b}}$ & $\mathbf{3 7 . 3 9}^{\mathrm{c}}$ \\
\hline $\mathbf{3}$ & 7 day & $32.32^{\mathrm{d}}$ & $\mathbf{3 3 . 8 7}^{\mathrm{d}}$ \\
\hline $\mathbf{4}$ & 8 days & $31.92^{\mathrm{d}}$ & $\mathbf{2 6 . 9 3}^{\mathrm{e}}$ \\
\hline $\mathbf{5}$ & 9 days & $33.87^{\mathrm{c}}$ & $\mathbf{4 0 . 2 3}^{\mathrm{b}}$ \\
\hline $\mathbf{6}$ & 10 days & $78.01^{\mathrm{a}}$ & $\mathbf{6 0 . 6 2}^{\mathbf{a}}$ \\
\hline $\mathbf{7}$ & 11 days & $56.52^{\mathrm{b}}$ & $\mathbf{4 2 . 3 1}^{\mathbf{b}}$ \\
\hline LSD $(\mathbf{P} \leq \mathbf{0 . 0 5})$ & $\mathbf{1 . 5 4 6}$ & $\mathbf{2 . 0 0 3}$ \\
\hline
\end{tabular}

Note: 1 . Mean values in each column with the same superscript(s) do not differ significantly by DMRT $(\mathrm{P}=0.05)$, 2. The growth medium contained Vogel's salt solution (50X)@ $20 \mathrm{ml} / \mathrm{L}$, sucrose @ $60 \mathrm{~g} / \mathrm{l}, \mathrm{KH}_{2} \mathrm{PO}_{4} @ 0.75 \mathrm{~g} / \mathrm{l}$ and Peptone @ $3.0 \mathrm{~g} / \mathrm{l}$ 
Table.8 Effect of different nutrient media compositions on the yield of Butyrolactone I

\begin{tabular}{|c|c|c|c|}
\hline \multirow[t]{2}{*}{ C/N/P Source } & \multicolumn{3}{|l|}{ Media compositions } \\
\hline & Control (Vogel's medium) & Media I & Media II \\
\hline Vogel's salt solution (50X) & $20 \mathrm{ml}$ & $20 \mathrm{ml}$ & $20 \mathrm{ml}$ \\
\hline Sucrose & $15 \mathrm{~g}$ & $60 \mathrm{~g}$ & $60 \mathrm{~g}$ \\
\hline Peptone & 0 & 0 & $3.0 \mathrm{~g}$ \\
\hline $\mathrm{KH}_{2} \mathrm{PO}_{4}$ & 0 & 0 & $* 0.75$ to $1.0 \mathrm{~g}$ \\
\hline pH & 5.8 & 5.8 & 6.5 \\
\hline \multicolumn{4}{|l|}{ Fermentation conditions } \\
\hline pH & 5.8 & 6.5 & 6.5 \\
\hline Temp & $30^{\circ} \mathrm{C}$ & $30^{\circ} \mathrm{C}$ & $30^{\circ} \mathrm{C}$ \\
\hline Incubation period & 6 days & 10 days & 10 days \\
\hline Agitation & Nil & $0-12 \mathrm{~h}$ & 0-12 h \\
\hline \multicolumn{4}{|l|}{$\begin{array}{l}\text { Butyrolactone I yield } \\
(\mathrm{mg} / 100 \mathrm{ml})\end{array}$} \\
\hline A. terreus ITC-01 & 18 & 45 & $63(40)$ \\
\hline A. terreus ITC-14 & 23 & 57 & $71(24)$ \\
\hline
\end{tabular}

Note: 1. Mean values in each column with the same superscript(s) do not differ significantly by DMRT $(\mathrm{P}=0.05)$, 2. The values given in the bracket under Media II column represent the percent increase in the production of Butyrolactone I over Media I. 3. *In case of A.terreusITC-14 $\mathrm{KH}_{2} \mathrm{PO}_{4}$ was used @ $1.0 \mathrm{~g} / \mathrm{L}$

Effect of optimized nutrient media composition and fermentation conditions on the yield of Butyrolactone I

The observations on yield of Butyrolactone I from optimized media and conditions are presented in Table 8. It shows that when strains of A. terreus were grown in optimized fermentation conditions in media containing optimized concentrations of carbon, nitrogen and phosphorus nutrients (medium II) Butyrolactone I yield was enhanced by 24 to $40 \%$ higher compared to Vogel's media enriched with sucrose (medium I).

The A. terreus grown in optimized medium produced Butyrolactone I yield of 63 and 71 mg by ITC-01 and ITC-14 respectively which was significantly higher than yield in Vogel's medium with enriched sucrose concentration which produced 45 and $57 \mathrm{mg}$ of Butyrolactone I per $100 \mathrm{ml}$ of medium by ITC-01 and ITC-14 respectively.
From the results, the best medium composition for the enhanced production of Butyrolactone I by A. terreus strains was found to be "Vogel's salt solution (50X) 20 $\mathrm{ml} / \mathrm{L}$, Sucrose $6.0 \%$, Peptone $0.3 \%$ and $\mathrm{KH}_{2} \mathrm{PO}_{4} 0.075$ to $0.1 \%$, similarly initial media $\mathrm{pH}$ of 6.5 , agitation up to initial $12 \mathrm{~h}$ after inoculation, incubation period of 10 days and Incubation temperature of $30^{\circ} \mathrm{C}$, were found to be the optimum conditions for maximum production of Butyrolactone I by A. terreus ITC-01 and ITC-14.

\section{References}

Domsch, K.H, Gams W., and Anderson, T.H.: Compendium of Soil Fungi. Academic Press, London (1980).

Hasegawa, Y., Fukuda T., Hagimori, K., Tomoda, H., and Omura, S.: Tensyuic acids, new antibiotics produced by Aspergillus niger FK1-2342. Chem Pharm. Bull. 55:1381-1341 (2007).

Takahashi, I., N. Ojima, K., Ogura, and Seto. 
S.: Purification and characterization of dimethylallyl pyrophosphate: aspulvinone dimethyl allyl transferase from Aspergillus terreus. Biochemistry. 17: 2696-2702 (1978).

Curtis, R. F., Hassall, C. H., Jones, D. W. and Williams, T., W.: The biosynthesis of phenols. II. Asterric acid, a metabolic product of Aspergillus terreus. Thom. J. Chem. Soc. 1960:4836-4842(1960).

Kaji, A. T., Iwata, N., Kiriyama, S., Wakusawa, and Miyamoto, K.: Four new metabolites of Aspergillus terreus. Chem. Pharm. Bull. (Tokyo). 42:16821684 (1994).

Kiriyama, N., K., Nitta, Y., Sakaguchi, Y., Tagushi, and Yamamoto. Y.: Studies on the metabolic products of Aspergillus terreus. III. Metabolites of the strain IFO 8835. Chem. Pharm. Bull. (Tokyo) 25:2593-2601 (1977).

Alberts, A. W. J., Kuron, V., Hunt, J., Huff, J., Hoffman, J., Rothrock, M., Lopez, H., Joshua, E., Harris, A., Patchett, R., Monaghan, S., Currie, E., Stapley, G., Albers-Schonberg, O., Hensens, J., Hirshfield, K., Hoogsteen, J., Lieschand, J., and Springer.: Mevinolin: a highly potent competitive inhibitor of hydroxyl methylglutaryl-coenzyme A reductase and a cholesterol-lowering agent. Proc. Natl. Acad. Sci. USA. 77:3957-3961 (1980).

Greenspan, M. D., and Yudkovitz, J. B.:Mevinolinic acid biosynthesis by Aspergillus terreus and its relationship to fatty acid biosynthesis. J. Bacteriol.162: 704-707 (1985).

Cho, K.M., Kim, W.G., Lee, C.K., and Yoo, I.D.: Terreulactones A, B, C, and D: Novel Acetylcholinesterase Inhibitors Produced by Aspergillus terreus I. Taxonomy, Fermentation, Isolation and Biological Activities. J Antibiot.56: 344-350 (2003).

Ling, K.H., Yang, C.K., Kuo, C., and Kuo, M. Solvent systems for improved isolation and separation of Territrems A \& B. Appl. Environ. Microbiol.44: 860-863
(1982).

Ling, K.H., Liou, H. H., Yang, C. M., and Yang, C.K.: Isolation, chemical structure, acute toxicity, and some physicochemical properties of Territrem C from Aspergillus terreus. Appl. Environ. Microbiol.47: 98-100 (1984).

Han, H., Yang, Y., Olesen, S.H., Becker, A., Betzi, A., and Schonbrunn, E.:The Fungal Product Terreic Acid Is a Covalent Inhibitor of the Bacterial Cell Wall Biosynthetic Enzyme UDP- $N$ Acetylglucosamine 1-Carboxy vinyltransferase (MurA), Biochemistry. 49: 4276-4282 (2010).

Kitagawa, M., Higashi, H., Takahashi, I. S., Okabe, T., Ogino, H., Taya, Y., Nishimura, S., and Okuyama, A.: A cyclin-dependent kinase inhibitor, butyrolactone I, inhibits phosphorylation of RB protein and cell cycle progression. Oncogene. 9: 25492557 (1994).

Malumbres, M., and Barbacid, M.: Mammalian cyclin-dependent kinases. Trends Biochem. Sci. 30:630-41 (2005).

Sinha, R.N.: Interrelations of physical, chemical and biological variables in the deterioration of stored grains. In grain storage: Part of a system. Pp. 15-47. Sinha, R.N. and Muir, W.E. ed. Avi Publishing Company, Westport, Connecticut, USA (1973).

Hesseltine, C.W., Conditions leading to mycotoxins contamination of food and feeds. Mycotoxins and other fungal related food problems. $\mathrm{Pp}$ 1-22. Rodricks, J.V. ed. American Chemical Society. Washington, D.C., USA (1974).

Schimmel, T.G., and S. J. Parsons.: High purity, high yield procedure for butyrolactone I production from Aspergillus terreus. Biotechnology Techniques. 13:379-384 (1999).

Vogel, H, J.: A convenient growth medium for Neurospora (Medium N). Microbial Genetics Bulletin. 13:42-43 (1956).

Vogel, H. J., andBonnerd, H. 1956. A 
convenient growth medium for $E$. coli and some other micro-organisms (Medium E). Microbial Genetirs Bulletin. 13: 43-44.

Wefky, S.H., Abou-Elela, G.M., and ElBestawy, E.: Optimization of Fermentation conditions for bioactive compound production by marine bacterium Enterococcus faecium. Journal of Applied. Sciences Research. 5: 1445-1454 (2009).

Panda, B.P., Javed, S. and Ali, M.: Fermentation process optimization. Res. J. Microbiol. 2 (3), 201-208 (2007).

Lopez, J.L.C., Perez, J.A.S., Sevilla, J.M.F., Fernandez, F.G.A., Grima, E.M., and Chisti, Y.: Fermentation optimization for the production of lovastatin by Aspergillus terreus: use of response surface methodology. Journal of Chemical Technology and Biotechnology. 79: 119-1126 (2004).

Martin, J.F.: Control of antibiotic synthesis by phosphate. Adv. Biochem. Engg.6:105 (1977).

Lie, J.L., and Marth, E.H.: Aflotoxin formation by Aspergillus flavus and Aspergillus paraciticus in a casein substrate at different $\mathrm{pH}$ values. J. dairy Sci. 51: 1743-1747 (1968).

Little, T.M., and Hills, F.C. Agricultural Experimentation. John Wiley and Sons Inc, U.S.A (1978).

Castella, G., Minkvold, G.P., and Hyde, W.G.: Effect of temperature, incubation period and substrate on production of fusaprolife in by Fusarium subglutinans. Nat. Toxin. 7: 129-132 (1999).

Ramos, A.J., Laberia, N., Marin, S., Sanchis, V., and Magon, N.: Effect of water activity and temperature on growth and ochratoxin production by three strains of Aspergillus ochraceus on a barley extract medium and on barley grains. Int. J. Food Microbiol. 44:133-140 (1998).

Leal-Sánchez, M.V., R. Jiménez-Diaz, Maldonado-A. Barragán, A. Fernández., and J.L. Ruiz-Barba.: Optimization of bacteriocin production by batch fermentation of Lactobacillus plantarum Appl. Environ. Microbiol. 68: 4465-4471 (2002).

Roy K.M., Smith K.A., and Sanderson J.: Barriers to the use of a diagnostic oral microbiology laboratory by general dental practitioners. Brit. Dent. J. 86:345-347 (1999).

Nakagawa, M., A. Hirota, H. Sakai, and Isogai. A.: Terrecyclic acid A, a new antibiotic from Aspergillus terreus. I. Taxonomy, production, and chemical and biological properties. J. Antibiot.35:778-782 (1982).

Vinci, V. A., T. D. Hoerner, A. D. Coffman, T. G. Schimmel, R. L. Dabora, A. C. Kirpekar, C. L. Ruby, and R. W. Stieber.: Mutants of a lovastatin hyperproducing Aspergillus terreus deficient in the production of sulochrin. J. Ind. Microbiol. 8:113-120 (1991).

\section{How to cite this article:}

Rudresh, D.L., Ratnadeep Paul Choudhury and Anamika Nakul. 2019. Optimization of Nutrients and Process Parameters for Improved Production of Bioactive Metabolite Butyrolactone I by Aspergillus terreus strains under Submerged Fermentation. Int.J.Curr.Microbiol.App.Sci. 8(04): 614-624. doi: https://doi.org/10.20546/ijcmas.2019.804.067 